\title{
Point Mutations in the $\beta$-Tubulin of Phytophthora sojae Confer Resistance to Ethaboxam
}

\author{
Qin Peng, ${ }^{1}$ Zhiwen Wang, ${ }^{1}$ Yuan Fang, ${ }^{1}$ Weizhen Wang, ${ }^{1}$ Xingkai Cheng, ${ }^{1}$ and Xili Liu ${ }^{2, \dagger}$ \\ ${ }^{2}$ Department of Plant Pathology, Northwest Agricultural \& Forest University, Yangling, China
}

${ }^{1}$ Department of Plant Pathology, China Agricultural University, Beijing, China

Accepted for publication 24 September 2019.

ABSTRACT

\begin{abstract}
Ethaboxam is a $\beta$-tubulin inhibitor registered for the control of oomycete pathogens. The current study was established to determine the ethaboxam sensitivity of the plant pathogen Phytophthora sojae and investigate the potential for the emergence of fungicide resistance. The effective concentration for $50 \%$ inhibition $\left(\mathrm{EC}_{50}\right)$ of 112 Phytophthora sojae isolates exhibited a unimodal distribution with a mean $\mathrm{EC}_{50}$ for ethaboxam of $0.033 \mu \mathrm{g} / \mathrm{ml}$. Establishing this baseline sensitivity provided critical data for monitoring changes in ethaboxam-sensitivity in field populations. The potential for fungicide resistance was investigated using adaptation on ethaboxam-amended V8 agar, which resulted in the isolation of 20 resistant mutants. An assessment of the biological characteristics of the mutants including mycelial growth, sporulation, germination rate and pathogenicity indicated that the resistance risk in Phytophthora sojae was low to medium with no cross-resistance between ethaboxam and cymoxanil, metalaxyl, flumorph, and oxathiapiprolin being detected.
\end{abstract}

However, positive cross-resistance was found between ethaboxam and zoxamide for Q8L and I258V but negative cross-resistance for C165Y. Further investigation revealed that the ethaboxam-resistant mutants had point mutations at amino acids Q8L, C165Y, or I258V of their $\beta$-tubulin protein sequences. CRISPR/Cas9-mediated transformation experiments confirmed that the Q8L, C165Y, or I258V mutations could confer ethaboxam resistance in Phytophthora sojae and that the C165Y mutation induces high levels of resistance. Taken together, the results of the study provide essential data for monitoring the emergence of resistance and resistance management strategies for ethaboxam, as well as for improving the design of novel $\beta$-tubulin inhibitors for future development.

Keywords: $\beta$-tubulin inhibitor, ethaboxam, Phytophthora sojae, point mutation, resistance risk, resistant mechanism
Oomycetes are fungus-like eukaryotic microorganisms that have evolved both pathogenic and saprophytic lifestyles. The hosts of oomycetes include plants, insects, crustaceans, fish, vertebrate animals, and various microorganisms (Kamoun 2003; Phillips et al. 2008; Thines and Kamoun 2010). Oomycete infections can result in severe damage to economically important plants and animals as well as to species associated with forestry and natural ecosystems (Kamoun et al. 2015; Phillips et al. 2008). Among the plantpathogenic oomycetes, species belonging to the genus Phytophthora are responsible for some of the most devastating oomycete diseases of agriculture crops including Phytophthora capsici, a common pathogen with a broad host range (Lamour et al. 2012), Phytophthora infestans, the pathogen that triggered the Irish Famine in the mid-19th century (Haas et al. 2009; Yoshida et al. 2013), and Phytophthora sojae, which causes root and stem rot disease in soybean (Kaufmann and Gerdemann 1958; Tyler 2007) that results in losses of $\$ 200$ to 300 million in the United States every year and global losses of around $\$ 1$ to 2 billion (Tyler 2007). Many management strategies are applied to control the oomycete diseases during agricultural production, such as resistant varieties, chemical fungicides and cultural techniques. Although resistant varieties and chemical fungicides can provide a degree of control, the efficient management of oomycete diseases still presents big

†Corresponding author: X. Liu; seedling@cau.edu.cn

Funding: This work was funded by the National Key Research and Development Program of China (2018YFD0201000, 2017YFD0201602).

*The $\boldsymbol{e}$-Xtra logo stands for "electronic extra" and indicates that two supplementary tables are published online.

The author(s) declare no conflict of interest.

Modified: 19 Aug 2020.

(C) 2019 The American Phytopathological Society problem to agricultural production. For example, the resistance genes ( $\mathrm{R}$ genes) currently utilized do not provide protection against all the known races of oomycete pathogens (Whitham et al. 2016) and they can easily be overcome by the pathogens (Fry 2008). Furthermore, the discovery of novel resistance genes and the breeding of resistant cultivars are difficult and time consuming. Consequently, producers have adopted the use of synthetic chemical fungicides as a more viable means of diseases control (Whisson et al. 2011), such as metalaxyl and mefenoxam (Gisi and Sierotzki 2015). However, oomycete pathogens have their specific characteristics and are phylogenetically distinct from the true fungi, which result in many commonly used fungicides in true fungi diseases control are not effective in oomycete diseases control. As a result, the range of compounds available for the control of oomycete diseases is extremely limited (Beakes et al. 2012). Indeed, the Fungicide Resistance Action Committee (FRAC) have noted that there are very few fungicides that can be used for oomycete diseases control. Besides the limited number of anti-oomycete fungicides, the occurrence and development of fungicide resistance is another big problem for sustainable oomycete diseases control. It is urgently required to create and develop new anti-oomycete fungicides.

The anti-oomycete fungicide ethaboxam was developed by LG Life Sciences Ltd. in 1993 (Ra et al. 1995) and has been registered in Korea since 1998 (Kim et al. 2004). Ethaboxam belongs to the aminothiazole carboxamide group of fungicides and has a fairly broad spectrum with activity against many oomycete pathogens, including the causal organisms of Phytophthora diseases and some Pythium diseases such as Pythium graminicola and Pythium ultimum, but not Pythium aphanidermatum. Ethaboxam has also been found to inhibit the fungus Cladosporium resinae and Corynespora cassiicola, but not any other true fungi or bacterial isolates belonging to the Pseudomonas and Bacillus genera (Kim et al. 2004). Field trials have shown that ethaboxam can provide effective control of many important oomycete diseases, including 
potato late blight caused by Phytophthora infestans, cucumber downy mildew caused by Pseudoperonospora cubensis, pepper Phytophthora blight caused by Phytophthora capsici, and grape downy mildew caused by Plasmopara viticola (Islam et al. 2018; Kim et al. 1999; Zhang et al. 2005). In vitro experiments have shown that ethaboxam inhibits mycelial growth and sporulation in Phytophthora infestans and other pathogens (Kim 2001; Kim et al. 2002). Other studies have shown that ethaboxam has both preventive and curative activity and is a persistent and systemic fungicide (Kim et al. 2004). However, it produces no observable phytotoxicity in the leaves, stems or fruits of cucumber, potato, or pepper (Kim et al. 1999). In addition, no cross-resistance has been observed between ethaboxam and phenylamide or strobilurin fungicides (Kim 2001; Kim et al. 2002, 2003). Mode of action studies have revealed that exposure to ethaboxam for $30 \mathrm{~min}$ at $0.01 \mu \mathrm{g} / \mathrm{ml}$ can disrupt the microtubules of Phytophthora infestans, while the model fungus Aspergillus nidulans and mammalian cells (mouse) were unaffected, which indicates that ethaboxam has highly specific activity (Uchida et al. 2005). Based on structural similarities to zarilamide and effect of ethaboxam on microtubules, it is believed that ethaboxam exerts its activity by binding directly to the $\beta$-tubulin protein (Young 2015). To date, no field resistance has been observed in Phytophthora infestans isolates (Kim et al. 2003), while UV or chemical mutagen N-methyl-N'-nitro-Nnitrosoguanidine treatment failed to yield any resistant mutants in either Phytophthora infestans or Phytophthora capsici (Kim 2001; Kim et al. 2002), which indicates that the resistance risk of ethaboxam is relatively low.

The current study was established to determine the ethaboxam sensitivity in wild-type isolates of Phytophthora sojae and investigate the potential for the emergence of fungicide resistance. Having isolated several ethaboxam mutants, the molecular mechanism of resistance was investigated by assessing changes in the $\beta$-tubulin gene of the mutants and validated by CRISPR/Cas9based transformation experiments.

\section{MATERIALS AND METHODS}

Isolates and culture conditions. The wild-type Phytophthora sojae isolates used in the current study have been listed in Supplementary Table S1. All the isolates were cultured on V8 agar ( $100 \mathrm{ml}$ of V8 juice, $1.4 \mathrm{~g}$ of $\mathrm{CaCO}_{3}, 15 \mathrm{~g}$ of agar, and distilled water to 1 liter) in the dark at $25^{\circ} \mathrm{C}$, and maintained in 2-ml plastic tubes containing V8 medium slants under mineral oil at $18^{\circ} \mathrm{C}$ for longterm storage (Dorrance et al. 2008).

Baseline sensitivity of ethaboxam in Phytophthora sojae. The sensitivity of 112 Phytophthora sojae isolates to ethaboxam was determined in vitro using a mycelia assay. Ethaboxam ( $99 \%$ a.i.) was dissolved in dimethyl sulfoxide (DMSO) to produce a stock solution at $100 \mathrm{~g} /$ liter, which was kept in the dark at $4^{\circ} \mathrm{C}$ until required. The sensitivity tests were performed using V8 agar amended with ethaboxam at the following concentrations, $0,0.005,0.01,0.025$, $0.05,0.1$, or $0.2 \mu \mathrm{g} / \mathrm{ml}$, with the concentration of DMSO being limited to $0.1 \%$ ( vol/vol), which was found to cause no inhibition of growth in preliminary tests. An equivalent concentration of DMSO was used for the negative controls. Mycelia plugs ( $5 \mathrm{~mm}$ in diameter) were excised from the growing edges of 5-day-old Phytophthora sojae colonies and transferred to the test V8 plates. The colony diameters were measured perpendicularly after 4 days of darkness incubation at $25^{\circ} \mathrm{C}$. Three technical replicate plates were prepared for each treatment and the entire experiment was performed at least twice. The data collected were subjected to linear regression according to the method described by $\mathrm{Lu}$ et al. (2010) to estimate the effective concentration for $50 \%$ inhibition $\left(\mathrm{EC}_{50}\right)$.

Generation of ethaboxam-resistant Phytophthora sojae mutants. The ethaboxam-resistant mutants were produced by

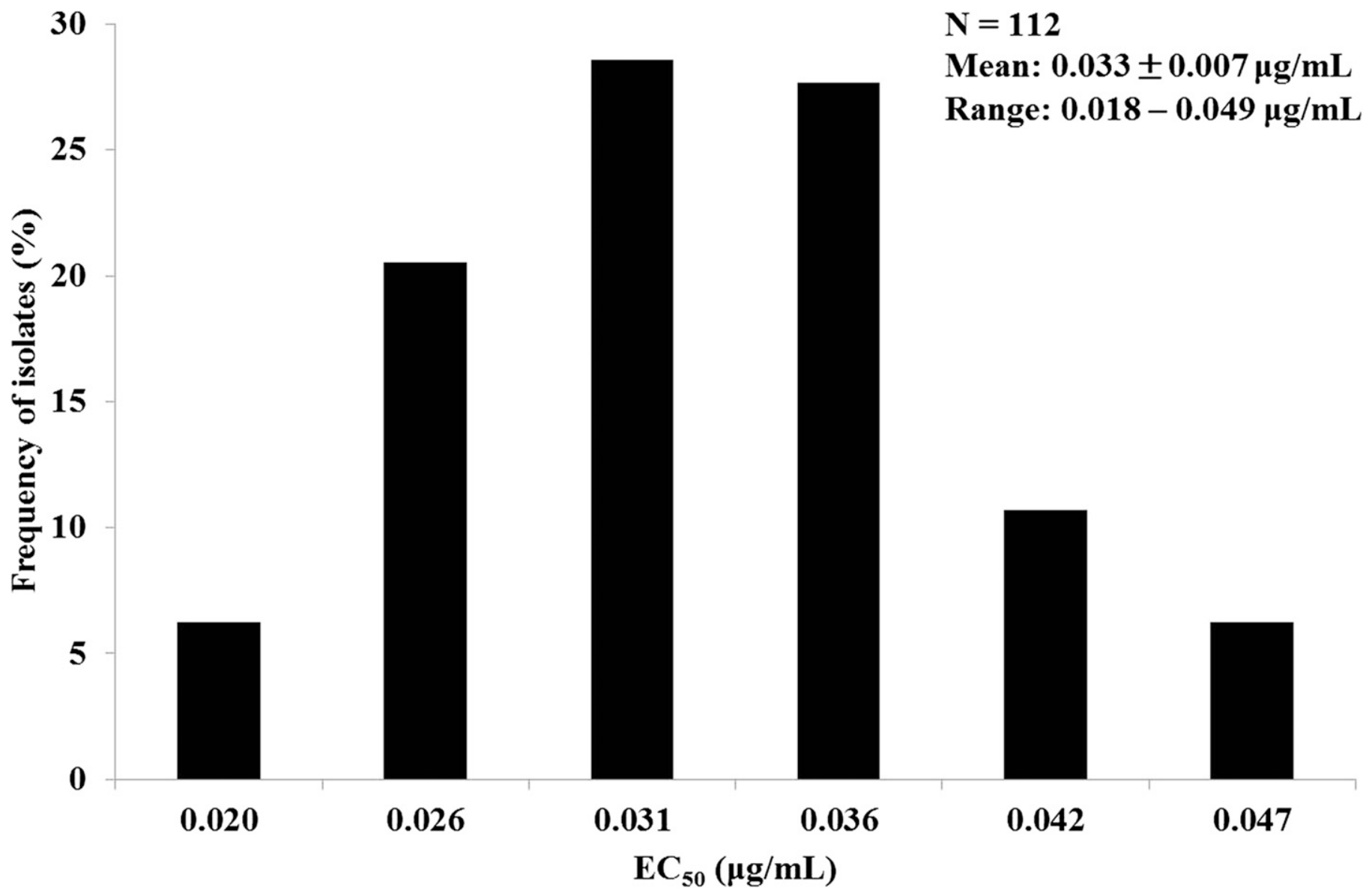

Fig. 1. Frequency distribution of ethaboxam effective concentration for $50 \%$ inhibition $\left(\mathrm{EC}_{50}\right)$ values for 112 field isolates of Phytophthora sojae. 
screening six randomly selected wild-type Phytophthora sojae isolates (PS6, PSDZT2-14, AH1306, CX1, PSJMS2, and P6497) on media containing ethaboxam at $0.2 \mu \mathrm{g} / \mathrm{ml}$ (the concentration at which all the wild-type isolates were unable to grow after 4 days incubation). The test media was inoculated with mycelial plugs and dark-incubated at $25^{\circ} \mathrm{C}$ for 15 to 30 days at which point the fastestgrowing portion of each colony was transferred to media amended

TABLE 1. The effective concentration for $50 \%$ inhibition $\left(\mathrm{EC}_{50}\right)$ value and stability of resistance in 10 Phytophthora sojae mutants with low resistance to ethaboxam

\begin{tabular}{lcccccc}
\hline & \multicolumn{2}{c}{ First generation } & & \multicolumn{2}{c}{ 10th generation } & \\
\cline { 2 - 3 } Isolate & $\mathrm{EC}_{50}(\mu \mathrm{g} / \mathrm{ml})$ & $\mathrm{RF}^{\mathrm{w}}$ & & $\mathrm{EC}_{50}(\mu \mathrm{g} / \mathrm{ml})$ & $\mathrm{RF}$ & $\mathrm{FSC}^{\mathrm{x}}$ \\
\hline WT-PSDZT2-14 & 0.05 & - & & 0.04 & - & - \\
PSDZT-M-7 & 0.55 & 11.00 & & 0.85 & 21.25 & 1.93 \\
PSDZT-M-14 & 0.69 & 13.80 & & 1.10 & 27.50 & 1.99 \\
PSDZT-M-15 & 1.55 & 31.00 & & 1.25 & 31.25 & 1.01 \\
PSDZT-M-19 & 0.91 & 18.20 & & 1.21 & 30.25 & 1.66 \\
WT-P6497 & 0.05 & - & & 0.05 & - & - \\
P6497-M-40z & 1.03 & 20.60 & & 1.04 & 20.80 & 1.01 \\
P6497-M-41 & 0.33 & 6.60 & & 0.38 & 7.60 & 1.15 \\
P6497-M-42 & 0.34 & 6.80 & & 0.32 & 6.40 & 0.94 \\
P6497-M-43 & 0.54 & 10.80 & & 0.43 & 8.60 & 0.80 \\
P6497-M-44 & 0.34 & 6.80 & & 0.33 & 6.60 & 0.97 \\
P6497-M-45 & 0.35 & 7.00 & & 0.34 & 6.80 & 0.97 \\
\hline
\end{tabular}

${ }^{\mathrm{w}} \mathrm{RF}$, resistance factor; RF for each mutant was calculated by dividing the $\mathrm{EC}_{50}$ of the mutant by that of the corresponding wild-type parental isolate.

${ }^{x}$ FSC, factor of sensitivity change; FSC was calculated by dividing the RF of the tenth subculture by that of the first.

y PSDZT-M, resistant mutants derived from parent isolate, WT-PSDZT2-14.

z P6497-M, resistant mutants derived from parent isolate, WT-P6497.

TABLE 2. The inhibition ratio and stability of resistance in 10 Phytophthora sojae mutants with high resistance to ethaboxam

\begin{tabular}{|c|c|c|c|c|}
\hline \multirow[b]{2}{*}{ Isolate } & \multirow[b]{2}{*}{$\mathrm{EC}_{50}(\mu \mathrm{g} / \mathrm{ml})$} & \multirow[b]{2}{*}{$\mathrm{RF}^{\mathrm{y}}$} & \multicolumn{2}{|c|}{$\begin{array}{c}\text { Inhibition ratio at } 100 \mu \mathrm{g} / \mathrm{ml} \\
\text { ethaboxam }(\%)\end{array}$} \\
\hline & & & $\begin{array}{c}\text { First } \\
\text { generation }\end{array}$ & $\begin{array}{c}\text { 10th } \\
\text { generation }\end{array}$ \\
\hline WT-PSDZT2-14 & 0.05 & - & 100 & 100 \\
\hline PSDZT-M-4 & $>50$ & $>1,000$ & 37 & 22 \\
\hline PSDZT-M-20 & $>50$ & $>1,000$ & 7 & 14 \\
\hline PSDZT-M-25 & $>50$ & $>1,000$ & 21 & 20 \\
\hline PSDZT-M-34 & $>50$ & $>1,000$ & 20 & 17 \\
\hline PSDZT-M-38 & $>50$ & $>1,000$ & 48 & 44 \\
\hline PSDZT-M-45 & $>50$ & $>1,000$ & 37 & 16 \\
\hline PSDZT-M-53 & $>50$ & $>1,000$ & 21 & 20 \\
\hline PSDZT-M-55 & $>50$ & $>1,000$ & 32 & 34 \\
\hline PSDZT-M-64 & $>50$ & $>1,000$ & 17 & 19 \\
\hline PSDZT-M-68 & $>50$ & $>1,000$ & 22 & 17 \\
\hline
\end{tabular}

y RF, resistance factor; RF for each mutant was calculated by dividing the effective concentration for $50 \%$ inhibition $\left(\mathrm{EC}_{50}\right)$ of the mutant by that of the corresponding wild-type parental isolate.

z PSDZT-M, resistant mutants derived from parent isolate, WT-PSDZT2-14. with increasing concentrations of ethaboxam $(1,2.5$, or $5 \mu \mathrm{g} / \mathrm{ml}$ for low resistant mutants, and $1,5,10,50$, or $100 \mu \mathrm{g} / \mathrm{ml}$ for highly resistant mutants). After 10 to 15 times of subculture, the surviving colonies were transferred to V8 agar containing ethaboxam at 5 or $100 \mu \mathrm{g} / \mathrm{ml}$ for a further three subcultures to stabilize the resistance. The $\mathrm{EC}_{50}$ values of the ethaboxam-resistant mutants were obtained by measuring their mycelial growth on V8 agar containing ethaboxam at $0,0.2,0.5,1,2.5$, or $5 \mu \mathrm{g} / \mathrm{ml}$ in the case of the low resistant mutants, and $0,10,25,50,100$, or $200 \mu \mathrm{g} / \mathrm{ml}$ for the highly resistant ones. The resistance factor (RF) for each mutant was calculated by dividing the $\mathrm{EC}_{50}$ of the mutant by that of the wildtype parental isolate.

Stability of ethaboxam-resistance. The stability of the ethaboxam-resistant Phytophthora sojae mutants was determined by comparing the $\mathrm{EC}_{50}$ or inhibition ratio on ethaboxam at $100 \mu \mathrm{g} / \mathrm{ml}$ of the first and 10th generation after 10 rounds of successive subculture on V8 agar in the absence of fungicide. The wild-type parental isolates were also assessed for comparison. Mycelial plugs were cut from the edge of 5-day-old colonies and placed in the center of fresh plates (one plug per plate) and dark-incubated at $25^{\circ} \mathrm{C}$ for 5 days. The $\mathrm{EC}_{50}$ values or inhibition ratios on $100 \mu \mathrm{g} / \mathrm{ml}$ of ethaboxam of each culture were tested after the first and 10th subculture. The RFs or inhibition ratios were calculated for the first and 10th subculture and the factor of sensitivity change (FSC) was then calculated by dividing the RF of the 10th subculture by that of the first. Each treatment consisted of three replicate plates, with the entire experiment being conducted twice.

Mycelial growth. The mycelial growth of the ethaboxamresistant mutants and the wild-type parental isolates were assessed on fungicide-free $\mathrm{V} 8$ agar at $25^{\circ} \mathrm{C}$. The colony diameters were measured perpendicularly after 6 days dark-incubation. Each treatment consisted of three replicate plates with the entire experiment being performed twice.

Sporulation and cyst germination. The zoospore production of the ethaboxam-resistant mutants and parental isolates were compared after 5 days culture on fungicide-free agar. The production of zoospores was induced by repeatedly washing the plates with distilled water according to the protocols of previous studies (Eye et al. 1978; Ho and Hickman 1967). The number of zoospores was quantified using a hemacytometer to estimate the number of zoospores per square centimeter of culture. The germination rate of the cystospores was assessed on water agar according to the protocol of a previous study (Bi et al. 2011). In detail, $100 \mu \mathrm{l}$ of zoospore suspension $\left(10^{4}\right.$ zoospores $\left./ \mathrm{ml}\right)$ was plated on $0.8 \%$ water agar medium. After $12 \mathrm{~h}$ dark-incubation at $25^{\circ} \mathrm{C}$, the percent germination of each isolate was estimated under a light microscope. Cystospores were considered to have germinated if the length of their germ tube was greater than the diameter of the cystospore. Each treatment consisted of three replicate plates, with the entire experiments being performed twice.

Pathogenicity assay. The pathogenicity of the ethaboxamresistant mutants and their parental isolates were determined by Phytophthora sojae infection assays on soybean hypocotyls. A $5 \mathrm{~mm}$ mycelial plug was inoculated onto etiolated hypocotyl of

TABLE 3. Fitness parameters of ethaboxam-resistant Phytophthora sojae mutants compared with their wild-type parental isolates ${ }^{\mathrm{y}}$

\begin{tabular}{|c|c|c|c|}
\hline Isolate & Colony diameter $(\mathrm{mm})$ & Zoospore production $\left(\times 10^{4} / \mathrm{cm}^{2}\right)$ & Lesion length $(\mathrm{cm})$ \\
\hline WT-P6497 & $(75.50 \pm 0.84) a$ & $(4.67 \pm 1.37) \mathrm{a}$ & $(9.50 \pm 1.29) \mathrm{a}$ \\
\hline P6497-M-40 & $(65.50 \pm 0.55) \mathrm{e}$ & $(1.00 \pm 0.00) b$ & $(6.65 \pm 1.02) \mathrm{c}$ \\
\hline P6497-M-41 & $(69.50 \pm 0.84) d$ & $(1.50 \pm 0.55) b$ & $(7.88 \pm 0.85) a b c$ \\
\hline P6497-M-42 & $(72.83 \pm 1.47) b c$ & $(1.00 \pm 0.00) b$ & $(6.83 \pm 0.78) b c$ \\
\hline P6497-M-43 & $(73.17 \pm 2.14) b$ & $(1.00 \pm 0.00) b$ & $(8.50 \pm 1.96) a b$ \\
\hline P6497-M-44 & $(72.83 \pm 0.75) b c$ & $(1.33 \pm 0.52) b$ & $(7.46 \pm 0.96) a b c$ \\
\hline P6497-M-45 & $(70.83 \pm 1.17) \mathrm{cd}$ & $(1.33 \pm 0.52) b$ & $(6.14 \pm 0.72) \mathrm{c}$ \\
\hline$P^{\mathrm{z}}$ & 0.0001 & 0.0001 & 0.0004 \\
\hline
\end{tabular}

y Means ( \pm standard error) in a column followed by the same letter are not significantly different at $P<0.05$ based on Tukey's multiple comparisons tests.

z Probability based on one-way analysis of variance. 
1-week-old soybean seedling (cultivar Williams), which was grown at $25^{\circ} \mathrm{C}$ in the dark. The lengths of the resulting lesion on hypocotyls were measured after 3 days dark incubation at $25^{\circ} \mathrm{C}$. Each treatment consisted of 10 replicate seedlings, with the entire experiment being conducted twice.

Sequence analysis of the $\beta$-tubulin gene. Total genomic DNA was extracted from the ethaboxam-resistant mutants and their parental isolates using a protocol described in a previous study (Chen et al. 2012). The full-length $\beta$-tubulin was amplified using EasyTaq DNA Polymerase (Beijing TransGen Biotech Co., Ltd.) with the following sequence-specific primers, which were designed according to the reference $\beta$-tubulin gene of Phytophthora sojae from the Phytophthora sojae genome, V3.0 (https://mycocosm.jgi. doe.gov/Physo3/Physo3.home.html): Ps-beta-F:5'-CGTGCGTCA AACATAGCAGG-3' and Ps-beta-R: 5'-TTAGAACGTACCGG CTGCTC-3'. The PCR conditions were as follows: 5 min at $95^{\circ} \mathrm{C}$ for initial denaturation followed by 35 cycles of $30 \mathrm{~s}$ denaturation at $95^{\circ} \mathrm{C}, 30 \mathrm{~s}$ annealing at $60^{\circ} \mathrm{C}$, and $3 \mathrm{~min}$ extension at $72^{\circ} \mathrm{C}$ and $10 \mathrm{~min}$ final extension at $72^{\circ} \mathrm{C}$. The resulting PCR products were Sanger-sequenced by Beijing Tsingke Biotech Co., Ltd. The final sequences were aligned and analyzed using DNAMAN (Version 8) and SnapGene (Version 1.1.3) software with the default parameters.

Cross-resistance assay. The sensitivity of the ethaboxamresistant mutants and wild-type isolates to five fungicides belonging to different chemical groups, including zoxamide, cymoxanil, metalaxyl, flumorph, and oxathiapiprolin, were assessed using the mycelia assay described above. The concentrations used for each fungicide are listed in Supplementary Table S2.

CRISPR/Cas9-mediated site-mutation of $\beta$-tubulin gene in Phytophthora sojae. The three point mutations detected in the $\beta$-tubulin of the ethaboxam-resistant mutants (Q8L, I258V, and $\mathrm{C} 165 \mathrm{Y}$ ) were transformed into the susceptible wild-type isolate P6497, for which the entire genome has been sequenced, to validate their association with the ethaboxam resistance observed. The transformation vectors were prepared according to the protocol of a previous study (Fang and Tyler 2016), with all enzyme digestions (New England BioLabs Inc.), gel extractions (Beijing TransGen Biotech Co., Ltd.), and ligations (New England BioLabs Inc.) being performed according to the protocols recommend by the manufacturers. Three homology-directed repair (HDR) donor vectors were constructed by cloning the homologous $1,000 \mathrm{bp} 5^{\prime}$ and $3^{\prime}$ flanking arms outside the target sites and infusing the PCR fragments into the pBluescript II KS+ plasmid using the In-Fusion HD Cloning Kit (Takara Biomedical Technology Co., Ltd., Beijing, China), respectively. One sgRNA (PsBTsgRNA1-ACCGGGGA AACGCAGGCACG) was designed using the online sgRNA Designer (https://portals.broadinstitute.org/gpp/public/analysis-tools/ sgrna-design) (Doench et al. 2014). The sgRNA construct was cloned into plasmid pYF2.3G-Ribo-sgRNA. The integrity of both the sgRNA vector and HDR vectors were confirmed by DNA sequencing.

The transformation itself was accomplished using the protocol described by Fang and Tyler (2016), with minor modification. The Phytophthora sojae strain was cultured on nutrient pea broth agar plate. After 4 days, eight mycelium discs were cut from the edge of the colony and cultured in 300-ml flask containing $50 \mathrm{ml}$ of nutrient pea broth. Three days after incubation, the Phytophthora sojae mycelium mats from three flasks were harvested for protoplast preparation. All other steps were performed as in the previous protocol. The transformants were first screened in pea broth medium containing geneticin at $30 \mu \mathrm{g} / \mathrm{ml}$ (AG Scientific) and subsequently on V8 agar amended with geneticin at $50 \mu \mathrm{g} / \mathrm{ml}$. The mycelia of the transformants were collected for genomic DNA extraction and the PCR products of the full-length $\beta$-tubulin in all transformants were Sanger-sequenced by Beijing Tsingke Biotech Co., Ltd. The final sequences were aligned and analyzed using DNAMAN (Version 8) and SnapGene (Version 1.1.3) software with the default parameters. The ethaboxam sensitivity of the single

spore isolated transformants was assessed using the sensitivity assay described above.

CRISPR/Cas9-mediated complementation of $\beta$-tubulin gene in Phytophthora sojae. In order to further validate the role of the $\beta$-tubulin mutations, the three wild-type nucleotides were reintroduced into the resistant transformants (T-Y165-167, T-V258172, and T-L8-24) by CRISPR/Cas9-mediated complementation. One sgRNA (PsBTsgRNA2-GAGAACCGAGTCGATAAGCT)

A

WT-P6497 P6497-M-40 P6497-M-41 P6497-M-42 P6497-M-43 P6497-M-44 P6497-M-45

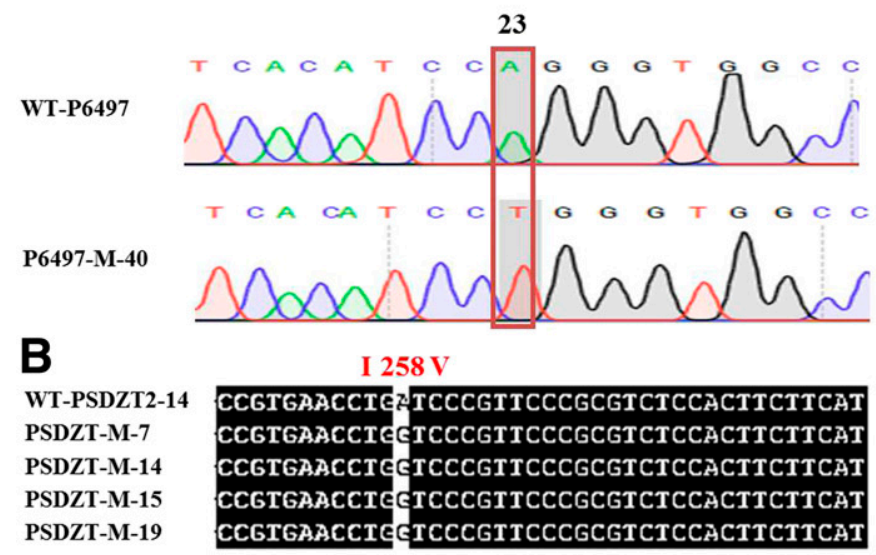

WT-PSDZT2-14

PSDZT-M-7

\section{C}

WT-PSDZT2-14 PSDZT-M-4 PSDZT-M-20 PSDZT-M-25 PSDZT-M-34 PSDZT-M-38 PSDZT-M-45 PSDZT-M-53 PSDZT-M-55 PSDZT-M-64 PSDZT-M-68

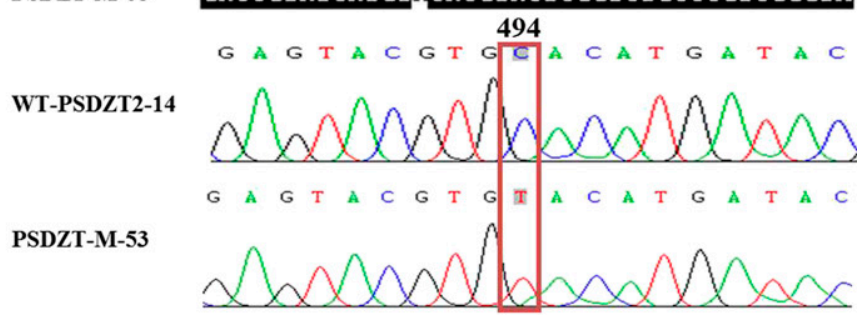

Fig. 2. Multiple sequence alignment and sequencing chromatograms of the $\beta$-tubulin gene from ethaboxam-resistant Phytophthora sojae mutants and the corresponding sensitive parental isolates P6497 and PSDZT2-14. A, Low resistant mutants from WT-P6497. B, Low resistant mutants from WT-PSDZT214. C, High resistant mutants from WT-PSDZT2-14.

Q $8 \mathrm{~L}$

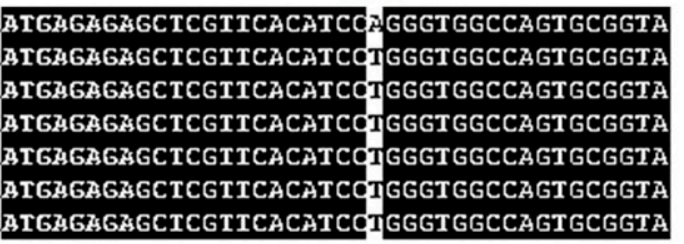
. 
vector and three HDR donor vectors were prepared for back transformation according to the details described above.

The transformation experiment was accomplished according to the protocol described above with minor modification. The transformants were first screened in pea broth medium containing oxathiapiprolin at $0.005 \mu \mathrm{g} / \mathrm{ml}$ and subsequently on V8 agar amended with oxathiapiprolin at $0.01 \mu \mathrm{g} / \mathrm{ml}$. All other steps were performed as the described protocol. The ethaboxam sensitivity of the complemented transformants was assessed using the sensitivity assay described above.

Statistical analysis. The experiment data generated in mycelial growth, sporulation and cyst germination, and pathogenicity was analyzed by Data Processing System software version 7.05 (DPS ver. 7.05). Statistical differences between wild-type isolates and mutants were analyzed using a one-way analysis of variance statistical test with Tukey's multiple comparisons tests. $P<$ 0.05 were considered statistically significant.

\section{RESULTS}

Baseline sensitivity of ethaboxam in Phytophthora sojae. The $\mathrm{EC}_{50}$ values of 112 Phytophthora sojae field isolates exposed to ethaboxam ranged between 0.018 and $0.049 \mu \mathrm{g} / \mathrm{ml}$, with a mean of $0.033 \mu \mathrm{g} / \mathrm{ml}$. There was a 2.72 -fold difference between the maximum and minimum $\mathrm{EC}_{50}$ values and the frequency distribution conformed to a unimodal curve (Fig. 1).

Generation of ethaboxam-resistant Phytophthora sojae mutants. A total of 20 mutants were recovered after adaptation on ethaboxam-amended media, 14 from the parental isolate PSDZT214 (PSDZT-M-4, 7, 14, 15, 19, 20, 25, 34, 38, 45, 53, 55, 64, and 68), and six from P6497 (P6497-M-40, 41, 42, 43, 44, and 45) (Tables 1 and 2). Although the $\mathrm{EC}_{50}$ values for the low resistant mutants (PSDZT-M-7, 14, 15, 19, and P6497-M-40, 41, 42, 43, 44, and 45) were accurately estimated using the linear regression (Table 1), it was not possible to obtain precise $\mathrm{EC}_{50}$ values for the highly resistant mutants (PSDZT-M-4, 20, 25, 34, 38, 45, 53, 55, 64, and $68)$ due to the solubility limit of ethaboxam. None of the highly resistant mutants incurred a $50 \%$ growth suppression even at an ethaboxam concentration of $100 \mu \mathrm{g} / \mathrm{ml}$, which indicates that their $\mathrm{EC}_{50}$ values are greater than the concentrations tested, and that therefore their corresponding $\mathrm{RF}$ values $\left(\mathrm{RF}=\mathrm{EC}_{50}\right.$ of the resistant mutant/EC $\mathrm{E}_{50}$ of the parent isolate) were in excess of 1,000 (Table 2). No ethaboxam-resistant mutants were obtained from any of the other four Phytophthora sojae isolates tested, including PS6, AH1306, CX1, and PSJMS2.

Stability of ethaboxam resistance. The RFs of the 10th generation of ethaboxam low resistant mutants ranged from 6.40 to 31.25 , with slightly altered RFs comparing to that of the first generation (Table 1). However, the RFs remained above 6, which was the same level as the first generation. The inhibition ratios on ethaboxam at $100 \mu \mathrm{g} / \mathrm{ml}$ of the 10 th generation of ethaboxam highly resistant mutants remained below $50 \%$, which was the same level as the first generation (Table 2). These results indicated that the resistance was stable in all 20 of the Phytophthora sojae mutants.

Mycelial growth, sporulation, and pathogenicity of mutants. Given that the parental isolate PSDZT2-14 could not produce zoospores and completely lacked pathogenicity on soybean seedlings, only the six ethaboxam-resistant mutants derived from isolate P6497 were assessed. The results indicated that mycelial growth of the mutants was significantly reduced $(P=$ 0.0001) compared with the parental isolate P6497 (Table 3). In addition, the growth rate of the mutants was found to vary

TABLE 4. Cross-resistance between ethaboxam and five other fungicides

\begin{tabular}{|c|c|c|c|c|c|c|c|}
\hline \multirow[b]{2}{*}{ Isolate } & \multirow[b]{2}{*}{ Substitution ${ }^{y}$} & \multicolumn{6}{|c|}{$\mathrm{EC}_{50}(\mu \mathrm{g} / \mathrm{ml})^{\mathrm{z}}$} \\
\hline & & Ethaboxam & Zoxamide & Oxathiapiprolin $\left(\times 10^{-4}\right)$ & Cymoxanil & Metalaxyl & Flumorph \\
\hline WT-PSDZT2-14 & WT & 0.05 & 0.02 & 5.16 & 0.94 & 0.16 & 0.48 \\
\hline WT-DZT1-15 & WT & 0.03 & 0.03 & 5.97 & 1.01 & 0.23 & 0.49 \\
\hline WT-AH1402 & WT & 0.03 & 0.02 & 4.74 & 5.70 & 0.16 & 0.48 \\
\hline WT-HLYF-3 & WT & 0.03 & 0.00 & 3.69 & 1.48 & 0.31 & 0.42 \\
\hline WT-PSSJD-07-3 & WT & 0.03 & 0.02 & 6.29 & 1.00 & 0.34 & 0.45 \\
\hline WT-CX-7 & WT & 0.04 & 0.03 & 1.99 & 1.20 & 0.30 & 0.36 \\
\hline WT-LS10 & WT & 0.03 & 0.03 & 5.63 & 0.73 & 0.17 & 0.42 \\
\hline WT-P6497 & WT & 0.05 & 0.02 & 4.92 & 1.76 & 0.16 & 0.38 \\
\hline Mean WT & & 0.03 & 0.02 & 5.09 & 1.50 & 0.24 & 0.42 \\
\hline PSDZT-M-7 & $\mathrm{I} 258 \mathrm{~V}$ & $0.55(11.0)$ & $0.09(4.5)$ & 3.88 & 1.69 & 0.20 & 0.51 \\
\hline PSDZT-M-14 & $\mathrm{I} 258 \mathrm{~V}$ & 0.69 (13.8) & $0.15(7.5)$ & 4.73 & 1.17 & 0.14 & 0.62 \\
\hline PSDZT-M-19 & $\mathrm{I} 258 \mathrm{~V}$ & $0.91(18.2)$ & $0.07(3.5)$ & 4.44 & 1.24 & 0.46 & 0.77 \\
\hline P6497-M-44 & Q8L & $0.34(6.8)$ & $0.11(5.5)$ & 3.45 & 2.89 & 0.32 & 0.39 \\
\hline P6497-M-45 & Q8L & $0.35(7.8)$ & $0.12(6.0)$ & 3.29 & 2.74 & 0.38 & 0.41 \\
\hline PSDZT-M-4 & $\mathrm{C} 165 \mathrm{Y}$ & $>50(>1,000)$ & $0.0006(0.03)$ & 4.54 & 0.54 & 0.12 & 0.34 \\
\hline PSDZT-M-20 & $\mathrm{C} 165 \mathrm{Y}$ & $>50(>1,000)$ & $0.002(0.10)$ & 4.07 & 0.73 & 0.15 & 0.50 \\
\hline PSDZT-M-25 & $\mathrm{C} 165 \mathrm{Y}$ & $>50(>1,000)$ & $0.001(0.05)$ & 4.06 & 2.31 & 0.16 & 0.51 \\
\hline PSDZT-M-34 & $\mathrm{C} 165 \mathrm{Y}$ & $>50(>1,000)$ & $0.001(0.05)$ & 4.70 & 0.43 & 0.09 & 0.37 \\
\hline PSDZT-M-38 & $\mathrm{C} 165 \mathrm{Y}$ & $>50(>1,000)$ & $0.0008(0.04)$ & 4.54 & 0.34 & 0.12 & 0.34 \\
\hline PSDZT-M-45 & $\mathrm{C} 165 \mathrm{Y}$ & $>50(>1,000)$ & $0.001(0.05)$ & 3.97 & 1.64 & 0.27 & 0.42 \\
\hline PSDZT-M-53 & $\mathrm{C} 165 \mathrm{Y}$ & $>50(>1,000)$ & $0.001(0.05)$ & 3.74 & $0.25(0.27)$ & 0.14 & 0.34 \\
\hline PSDZT-M-55 & $\mathrm{C} 165 \mathrm{Y}$ & $>50(>1,000)$ & $0.0009(0.05)$ & 2.6 & 0.53 & 0.19 & 0.37 \\
\hline PSDZT-M-64 & C165Y & $>50(>1,000)$ & $0.001(0.05)$ & 2.90 & 1.69 & $0.05(0.31)$ & 0.49 \\
\hline PSDZT-M-68 & $\mathrm{C} 165 \mathrm{Y}$ & $>50(>1,000)$ & $0.001(0.05)$ & 2.93 & 1.45 & 0.20 & 0.48 \\
\hline
\end{tabular}

y Amino acid substitution genotype based on DNA sequencing of the $\beta$-tubulin gene.

${ }^{\mathrm{z}}$ Estimated effective concentration for $50 \%$ inhibition $\left(\mathrm{EC}_{50}\right)$ value based on in vitro mycelia growth inhibition assays. Values in parentheses indicate resistance factor (RF) of mutants relative to their parental isolate. RF values $\geq 3$ or $\leq 0.33$ indicated only. 
significantly $(P=0.0001)$, with P6497-M-43 growing the fastest and P6497-M-40 the slowest (Table 3). There were also significant differences $(P=0.0001)$ between the zoospore production of the resistant mutants and wild-type isolate (Table 3), with the parental isolate P6497 producing as many as five times more zoospores (Table 3). However, although all the mutants produced smaller lesions compared with the parental isolate P6497, the difference was only significant $(P=0.0004)$ for three: P6497-M-40, P6497-M42, and P6497-M-45 (Table 3).
Sequence analysis of the $\boldsymbol{\beta}$-tubulin gene. The results of a previous study (Kim et al. 2003) and those of the cross-resistance experiment in current study provide persuasive evidence that ethaboxam could be a $\beta$-tubulin inhibitor. To investigate further, the $\beta$-tubulin genes of the ethaboxam mutants and their parental isolates were cloned and sequenced. Multiple sequence alignment revealed several point mutations at nucleotide positions 23,772 , and 494 (Fig. 2A, B, and C). These mutations resulted in amino acid substitutions at codons 8,258 , and 165 , respectively. At codon 8 ,

A
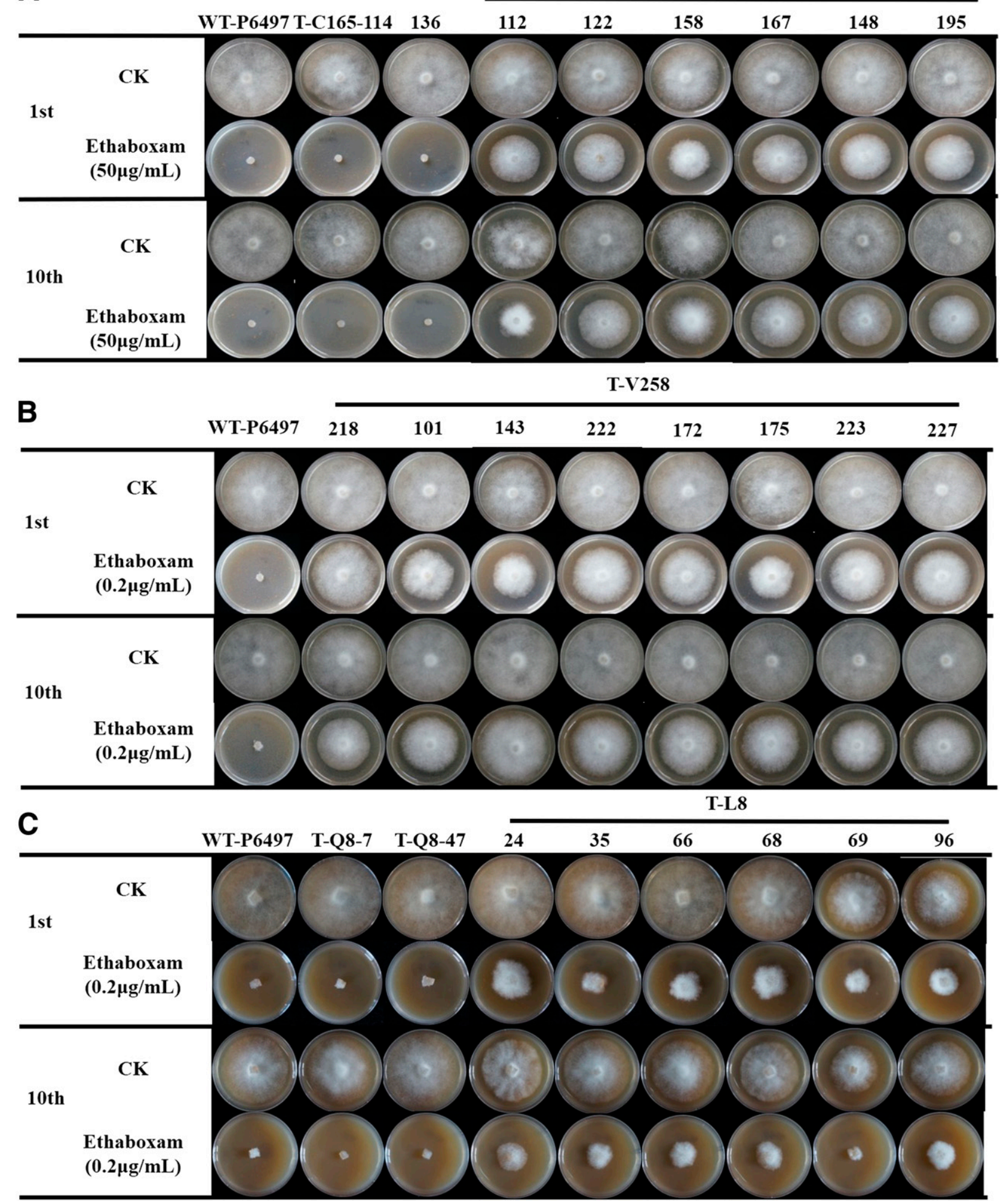

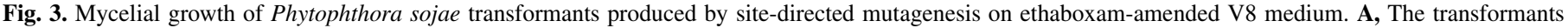
containing the Y165 mutation. B, The transformants containing the V258 mutation. C, The transformants containing the L8 mutation. 
glutamine was substituted for leucine (Q8L). At codon 258, isoleucine was substituted for valine (I258V). Cysteine was substituted for tyrosine at codon 165 (C165Y) (Fig. 2A, B, and C). In addition, the investigation revealed that the ethaboxamresistant mutants produced only single chromatogram peaks at nucleotide positions 23, 772, and 494 (Fig. 2A, B, and C), which indicated that the Q8L, I258V, and C165Y were homozygous in the ethaboxam-resistant mutants.

Cross-resistance assay. The ethaboxam-resistant mutants were treated with five fungicides (zoxamide, cymoxanil, metalaxyl, flumorph, and oxathiapiprolin) with different modes of action to determine whether there was any cross-resistance with ethaboxam. The mutants were found to be sensitive to all the fungicides tested, except zoxamide. Furthermore, it was noted that the low resistance mutants were slightly less sensitive to zoxamide, while the highly resistant mutants were much more sensitive. The results indicated that there was positive cross-resistance between ethaboxam and zoxamide for Q8L and I258V but negative cross-resistance for C165Y, but no cross-resistance between ethaboxam and the other four fungicides (Table 4).

CRISPR/Cas9-mediated site mutation of $\boldsymbol{\beta}$-tubulin gene in Phytophthora sojae. A total of 24 transformants were obtained by protoplast transformation using CRISPR/Cas9 technology and mutations were confirmed in the transformants, of which six contained the Y165 mutation (T-Y165-112, 122, 148, 158, 167, and 195), eight the V258 mutation (T-V258-101, 143, 172, 175, 218, 222, 223, and 227), and six the L8 mutation (T-L8-24, 35, 66, 68, 69, and 96), and four that contained the same amino acid sequence as the parent isolate (T-C165-114, T-C165-136, T-Q8-7, and T-Q847). The sensitivity of the transformants to ethaboxam was tested at the concentrations of $0.2 \mu \mathrm{g} / \mathrm{ml}$ for expected low resistant transformants and $50 \mu \mathrm{g} / \mathrm{ml}$ for expected highly resistant transformants. The test results indicated that the six transformants containing the Y165 mutation were able to grow on ethaboxam at $50 \mu \mathrm{g} / \mathrm{ml}$ (Fig. 3A), while the eight transformants containing the V258 mutation and the six transformants containing the L8 could grow on the media amended with ethaboxam at $0.2 \mu \mathrm{g} / \mathrm{ml}$ (Fig. 3B and C). In contrast, the four transformants containing the same amino acid sequence as the parental isolate failed to grow even at the lowest concentration $(0.2 \mu \mathrm{g} / \mathrm{ml})$ of ethaboxam (Fig. $3 \mathrm{~A}$ and $\mathrm{C}$ ).

Mycelial growth, sporulation, germination, and pathogenicity of transformants. The mycelial growth, sporulation, cystospore germination, and pathogenicity of the transformants (Y165 and V258) were compared with that of the parental isolate P6497. The mycelial growth of most of the transformants was equal to or significantly reduced compared with the parental isolate P6497, although one, T-Y165-195, grew faster $(P=0.0001)$ (Table 5). There were also significant differences $(P=0.0001)$ regarding zoospore production (Table 5). Of the eight V258 transformants, five produced significantly more zoospores than the parental isolate. However, all remaining transformants were not statistically different from the parental isolate. Conversely, five of eight Y165 transformants exhibited statistical lower zoospore germination rates, with the remainder not significantly different from the parental isolate $(P=0.0001)$. All the transformants produced smaller lesions on inoculated soybean seedlings, but only eight transformants were significantly smaller than those produced by the parental isolate $(P=0.0006)$ (Table 5$)$.

CRISPR/Cas9-mediated complementation of $\beta$-tubulin gene in Phytophthora sojae. A total of 24 transformants were obtained, of which seven were successfully complemented with C165 (SC-C165-17, 24, 54, 68, 72, 109, and 131) (Fig. 4A), six with I258 (SC-I258-15, 44, 83, 126, 170, and 182) (Fig. 4B), and eight with Q8 (SC-Q8-6, 7, 8, 14, 25, 63, 64, and 67) (Fig. 4C), as well as three that still contained the site-mutated amino acids, Y165 or V258 (SC-Y165-42, SC-V258-37, and SC-V258-47) (Fig. 4A and B). The ethaboxam sensitivity of the site-complemented transformants was tested on media containing ethaboxam at $0.2,1$, or $50 \mu \mathrm{g} / \mathrm{ml}$. The result showed that the seven transformants containing C165 were unable to grow on ethaboxam at 1 and $50 \mu \mathrm{g} / \mathrm{ml}$ (Fig. 5A), while the six transformants containing I258 and the eight containing Q8 could not grow even on ethaboxam at $0.2 \mu \mathrm{g} / \mathrm{ml}$ (Fig. $5 \mathrm{~B}$ and $\mathrm{C})$. In contrast, the two transformants, SC-V258-37 and SCV258-47, were able to grow on media containing ethaboxam at $0.2 \mu \mathrm{g} / \mathrm{ml}$, while a third SC-Y165-42 was able to grow on ethaboxam at $50 \mu \mathrm{g} / \mathrm{ml}$ (Fig. 5A and B).

\section{DISCUSSION}

Agricultural fungicides that target tubulin belong to three chemical classes, the benzimidazoles, the N-phenylcarbamates, and the benzamides (Young 2015). However, the N-phenylcarbamates and benzimidazoles have the same target as that of the benzamides and can be used to control diseases caused by true fungi, but not oomycetes. In contrast, the benzamides, which include zoxamide and ethaboxam, are effective in oomycetes. Indeed, ethaboxam and zoxamide are the only $\beta$-tubulin inhibitors registered for the control of oomycete diseases (Kim et al. 2002; Uchida et al. 2005; Young 2007) and fortunately the resistance risk for the two fungicides has been designated as low to medium by FRAC. However, there are many differences between the two fungicides.

TABLE 5. Comparison of fitness parameters for Phytophthora sojae transformants with altered $\beta$-tubulin sequences and their wild-type parental isolate ${ }^{y}$

\begin{tabular}{|c|c|c|c|c|}
\hline Isolate & Colony diameter (mm) & Zoospore production $\left(\times 10^{4} / \mathrm{cm}^{2}\right)$ & Germination rate $(\%)$ & Lesion length $(\mathrm{cm})$ \\
\hline WT-P6497 & $(70.83 \pm 0.98) b c$ & $(4.69 \pm 2.60) \mathrm{de}$ & $(61.67 \pm 3.51) a b c$ & $(7.10 \pm 0.36) \mathrm{a}$ \\
\hline T-V258-101 & $(72.33 \pm 4.37) b$ & $(7.00 \pm 2.36) \mathrm{cde}$ & $(56.00 \pm 5.29) \mathrm{bcd}$ & $(6.17 \pm 1.04) \mathrm{ab}$ \\
\hline T-V258-143 & $(61.67 \pm 1.21) \mathrm{ijk}$ & $(10.40 \pm 4.84) a b c$ & $(72.33 \pm 3.51) \mathrm{a}$ & $(2.97 \pm 1.45) b c$ \\
\hline T-V258-172 & $(68.50 \pm 0.89)$ bcdef & $(11.13 \pm 3.40) a b c$ & $(73.00 \pm 6.08) \mathrm{a}$ & $(4.70 \pm 1.47) a b c$ \\
\hline T-V258-175 & $(63.33 \pm 0.84)$ ghij & $(4.00 \pm 1.93) \mathrm{de}$ & $(69.00 \pm 5.20) a b$ & $(3.50 \pm 0.65) b c$ \\
\hline T-V258-218 & $(69.83 \pm 0.63)$ bcde & $(8.63 \pm 3.29) \mathrm{bcd}$ & $(60.67 \pm 4.73) a b c$ & $(2.80 \pm 1.22) b c$ \\
\hline T-V258-222 & $(57.83 \pm 0.55) \mathrm{k}$ & $(11.50 \pm 3.16) a b c$ & $(68.33 \pm 2.89) a b$ & $(3.55 \pm 1.34) a b c$ \\
\hline T-V258-223 & $(63.00 \pm 3.21) \mathrm{hij}$ & $(13.63 \pm 7.07) a b$ & $(68.00 \pm 8.89) \mathrm{ab}$ & $(3.47 \pm 1.27) b c$ \\
\hline T-V258-227 & $(69.50 \pm 1.21)$ bcdef & $(14.00 \pm 4.11) \mathrm{a}$ & $(72.00 \pm 2.00) \mathrm{a}$ & $(5.03 \pm 0.68) a b c$ \\
\hline T-C165-114 & $(60.17 \pm 1.47) \mathrm{jk}$ & $(1.67 \pm 0.82) \mathrm{e}$ & $(47.83 \pm 1.92) \mathrm{cde}$ & $(3.40 \pm 1.41) b c$ \\
\hline T-C165-136 & $(70.00 \pm 2.23) \mathrm{bcd}$ & $(4.50 \pm 1.05) \mathrm{de}$ & $(43.67 \pm 0.84) \mathrm{de}$ & $(3.88 \pm 1.40) a b c$ \\
\hline T-Y165-112 & $(67.33 \pm 1.47)$ cdefg & $(3.88 \pm 1.46) \mathrm{de}$ & $(44.00 \pm 5.29) \mathrm{de}$ & $(3.90 \pm 2.40) a b c$ \\
\hline T-Y165-122 & $(66.17 \pm 4.07)$ defgh & $(3.00 \pm 1.93) \mathrm{e}$ & $(56.44 \pm 1.26) \mathrm{bcd}$ & $(5.25 \pm 1.24) a b c$ \\
\hline T-Y165-148 & $(65.67 \pm 0.82) \mathrm{fghi}$ & $(3.38 \pm 1.06) \mathrm{de}$ & $(42.89 \pm 1.83) \mathrm{de}$ & $(2.57 \pm 0.45) b c$ \\
\hline T-Y165-158 & $(62.33 \pm 1.37)$ hij & $(1.75 \pm 0.71) \mathrm{e}$ & $(50.79 \pm 6.27) \mathrm{cde}$ & $(3.95 \pm 0.21) a b c$ \\
\hline T-Y165-167 & $(65.83 \pm 1.37)$ efgh & $(2.25 \pm 1.04) \mathrm{e}$ & $(41.33 \pm 6.43) \mathrm{e}$ & $(1.93 \pm 0.51) \mathrm{c}$ \\
\hline T-Y165-195 & $(82.50 \pm 0.75) \mathrm{a}$ & $(3.75 \pm 1.91) \mathrm{de}$ & $(44.95 \pm 1.97) \mathrm{de}$ & $(3.27 \pm 1.55) b c$ \\
\hline$P^{\mathrm{z}}$ & 0.0001 & 0.0001 & 0.0001 & 0.0006 \\
\hline
\end{tabular}

y Means ( \pm standard error) in a column followed by the same letter are not significantly different at $P<0.05$ based on Tukey's multiple comparisons tests.

z Probability based on one-way analysis of variance. 
For example, in addition to its activity against oomycetes, zoxamide also provides control of many true fungi including Botrytis cinerea, Monilinia fructicola, Venturia inaequalis, Mycosphaerella fijiensis, and Cercospora beticola (Egan et al. 1998), while ethaboxam only has high activity against oomycetes such as Phytophthora infestans, Phytophthora capsici, Phytophthora cubensis, and Plasmopara viticola (Islam et al. 2018; Kim et al. 1999, 2004; Zhang et al. 2005). Given the differences in the spectrum of pathogens affected by the two fungicides it is possible that they have different modes of action. Although detailed studies have shown that mutations in the $\beta$-tubulin gene or its overexpression do not result in zoxamide resistance in Phytophthora capsici (Bi et al. 2011, 2014), Phytophthora cactorum (Mei et al. 2014), and Pythium sylvaticum (Martinez et al. 2005), other studies have shown that separate mutations in the $\beta$-tubulin gene can confer resistance to zoxamide in B. cinerea (Cai et al. 2015) and Phytophthora sojae (Cai et al. 2016),
A

Site-complemented transformants
T-Y165-167

SC-Y165-42

- SC-C165-17

SC-C165-24

SC-C165-54

SC-C165-68

SC-C165-72

SC-C165-109

SC-C165-131

Consensus
B

Site complemented transformants
T-V258-172

SC-V258-37

SC-V258-47

[SC-I258-15

SC-I258-44

SC-I258-83

SC-I258-126

SC-I258-170

SC-I258-182

Consensus

C Site-complemented
transformants
T-L8-24

$\left\{\begin{array}{l}\text { SC-Q8-6 } \\ \text { SC-Q8-7 } \\ \text { SC-Q8-8 } \\ \text { SC-Q8-14 } \\ \text { SC-Q8-25 } \\ \text { SC-Q8-63 } \\ \text { SC-Q8-64 } \\ \text { SC-Q8-67 }\end{array}\right.$

Consensus<smiles>[AsH2][AsH2]</smiles>

GACCGTATCATGI ZCACGTACTCGGTC GACCGTATCATGTACACGTACTCGGTC GACCGTATCATGTGCACGTACTCGGTC GACCGTATCATGTGCACGTACTCGGTC GACCGTATCATGIGCACGTACTCGGTC GACCGTATCATGTGCACGTACTCGGTC GACCGTATCATGTGCACGTACTCGGTC GACCGTATCATGIGCACGTACTCGGTC GACCGTATCATGIGCACGTACTCGGTC geccgtatcatgt cecgtectcggtc<smiles>[Y10]1c[cH+]1</smiles><smiles>[AlH][AlH2]</smiles>
CCGTGAACCTESTCCCGTTCCCGCG
CCGTGAACCTEGTCCCGTTCCCGCG
CCGTGAACCTEGTCCCGTTCCCGCG
CCGTGAACCTEATCCCGTTCCCGCG
CCGTGAACCTEATCCCGTTCCCGCG
CCGTGAACCTEATCCCGTTCCCGCG
CCGTGAACCTEATCCCGTTCCCGCG
CCGTGAACCTEATCCCGTTCCCGCG
CCGTGAACCTEATCCCGTTCCCGCG
CCgTgZZCCtg tCCCgTtCCCgCg<smiles>[123In]</smiles>
AGCTCGTTCACATCOIGGGTGGCCAGTGC AGCTCGTTCACATCQAGGGTGGCCAGTGC AGCTCGTTCACATCCAGGGTGGCCAGTGC AGCTCGTTCACATCCAGGGTGGCCAGTGC AGCTCGTTCACATCCAGGGTGGCCAGTGC AGCTCGTTCACATCCAGGGTGGCCAGTGC AGCTCGTTCACATCQAGGGTGGCCAGTGC AGCTCGTTCACATCCAGGGTGGCCAGTGC AGCTCGTTCACATCCAGGGTGGCCAGTGC agctcgttcacatcc gggtggccagtgc

Fig. 4. Multiple sequence alignment of the $\beta$-tubulin genes from site-complemented transformants and the corresponding parental isolates, T-Y165-167, T-V258172, and T-L8-24, respectively. A, The site-complemented transformants from T-Y165-167. B, The site-complemented transformants from T-V258-172. C, The site-complemented transformants from T-L8-24. 
respectively. However, to date the mode of action of ethaboxam and possible resistance mechanisms or even reports of resistance in field populations or laboratory isolates have not be reported. Detailed studies of the resistance risk and the possible resistant mechanisms of ethaboxam are therefore long overdue.

The current study evaluated the $\mathrm{EC}_{50}$ values of 112 field isolates of Phytophthora sojae, which ranged from 0.018 to $0.049 \mu \mathrm{g} / \mathrm{ml}$ and established the baseline sensitivity for ethaboxam, with a mean $\mathrm{EC}_{50}$ of $0.033 \mu \mathrm{g} / \mathrm{ml}$, which is similar to the level of zoxamide sensitivity in Phytophthora sojae (Cai et al. 2016) and similar to the ethaboxam sensitivity of other Phytophthora species including Phytophthora hibernalis, Phytophthora syringae, Phytophthora nicotianae, and Phytophthora citrophthora (Gray et al. 2018). The distribution of the $\mathrm{EC}_{50}$ values for the Phytophthora sojae isolates exhibited a unimodal curve, which indicates that no natural spontaneous mutants had been detected, and that the baseline sensitivity of ethaboxam established in the current study can be used to monitor changes in the ethaboxam sensitivity of Phytophthora sojae in field populations. However, the current study also demonstrated that resistance could be induced in Phytophthora sojae, with 20 stable resistant mutants with different levels of resistance being recovered from ethaboxam adaptation experiments. Analysis of the $\beta$-tubulin gene of the resistant isolates identified three point mutations that resulted in changes to the amino acid sequence: Q8L, C165Y, and I258V. The L8 mutants, which were derived from the parental isolate P6497 were found to have low levels of resistance, while the Y165 and V258 mutants derived from PSDZT2-14, were found to have high and low levels of resistance, respectively. CRISPR/Cas9-mediated transformation experiments validated the hypothesis that Q8L, C165Y, and $\mathrm{I} 258 \mathrm{~V}$ resulted in resistance to ethaboxam, with the transformants containing L8, Y165, or V258 exhibiting levels of resistance similar to those found in the resistant mutants containing the same amino acid substitutions. In contrast, the negative transformants containing Q8, C165, or I258 remained sensitive to ethaboxam. Site-complementation experiments further validated the role of the three mutations in ethaboxam resistance, with the site-complemented transformants containing Q8,

A

SC-C165

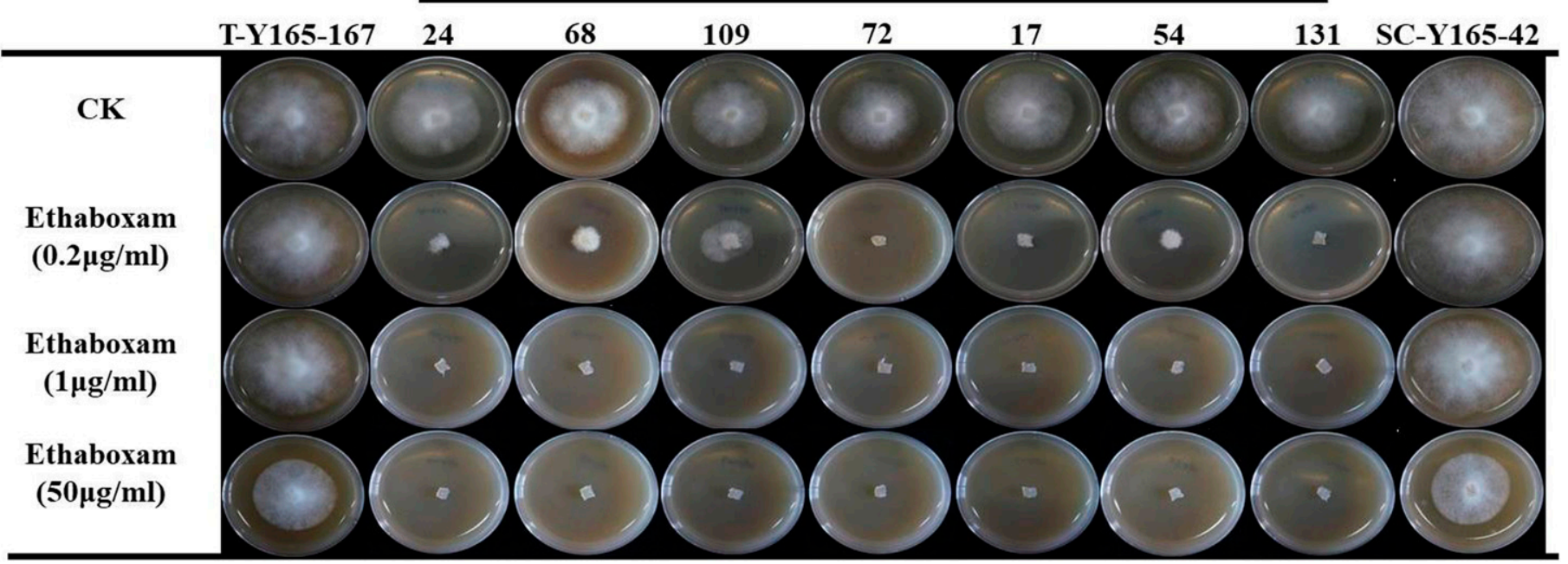

B

\section{SC-I258}

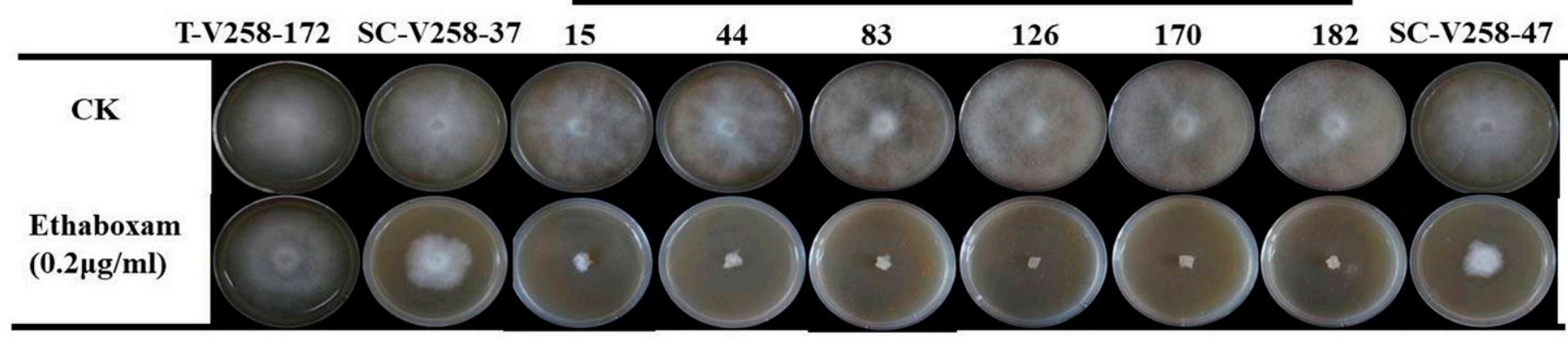

C

SC-Q8

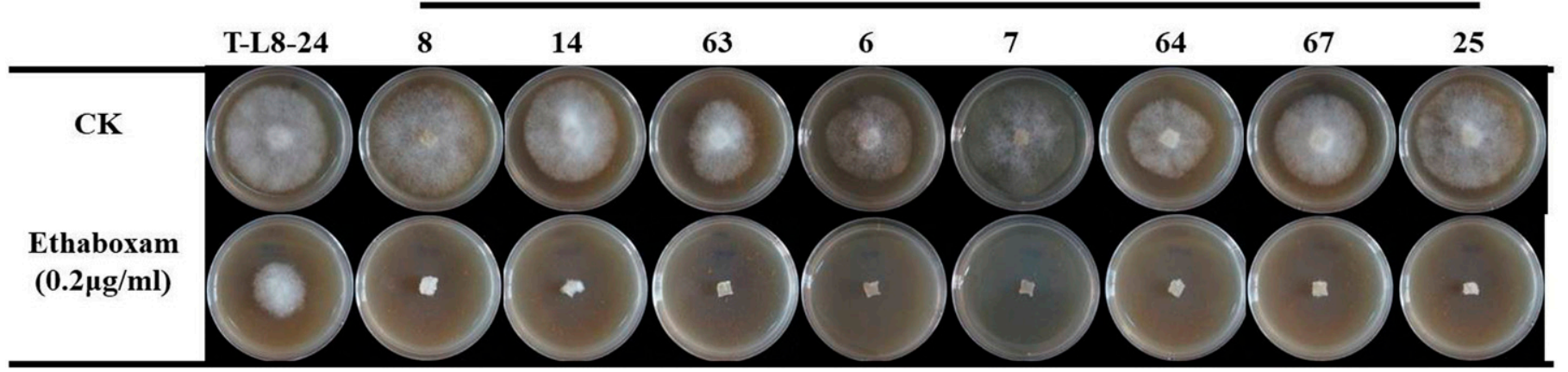

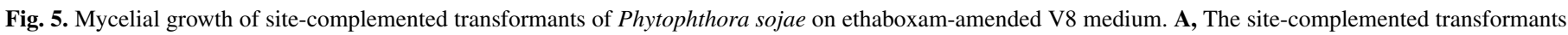

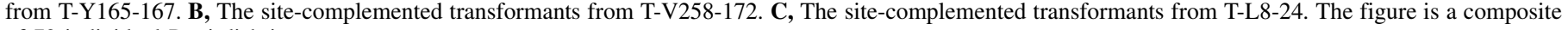
of 72 individual Petri dish images. 
$\mathrm{C} 165$, or $\mathrm{I} 258$ having restored sensitivity to ethaboxam. Taken together these results provide strong evidence that the Q8L, C165Y, and $\mathrm{I} 258 \mathrm{~V}$ substitutions in the $\beta$-tubulin of Phytophthora sojae result in resistance to ethaboxam.

The biological characteristics of the L8 mutants including mycelial growth rate, sporulation, and virulence were reduced compared with the parental isolate, which indicates that the mutation results in a fitness cost. However, since the parental isolate PSDZT2-14 does not produce zoospores or exhibit virulence on soybean seedlings, similar evaluations of the Y165 and V258 mutations could not be determined directly. However the transformants produced by site directed mutation were evaluated, it was discovered that the V258 mutation was associated with mycelial growth rates and virulence equal to or less than that of parental isolate and that sporulation and germination rates were equal or higher. Most of the Y165 transformants exhibited mycelial growth rates equal to or less than that of parental isolate and sporulation, germination, and virulence levels that were reduced. Taken together these results indicate that the resistance risk of the high resistance mutation Y165 was low, while that of the low resistance mutations L8 and V258 was medium. Therefore, the overall resistance risk for ethaboxam in Phytophthora sojae should be considered low to medium. However, given the limited number of compounds available for the control of oomycete pathogens, it is still important to monitor any changes to the ethaboxam sensitivity of wild populations of Phytophthora sojae to guard against the emergence of resistance in the field.

The observation that mutations were detected in the $\beta$-tubulin gene of the ethaboxam-resistant Phytophthora sojae isolates strongly suggest that $\beta$-tubulin is the target protein of ethaboxam, which is in agreement with a previous study that found ethaboxam can disrupt the integrity of microtubules in Phytophthora infestans (Uchida et al. 2005). It is therefore interesting to note that the crossresistance analysis found positive cross-resistance with the known $\beta$-tubulin inhibitor zoxamide for $\mathrm{Q} 8 \mathrm{~L}$ and $\mathrm{I} 258 \mathrm{~V}$, but negative cross-resistance for $\mathrm{C} 165 \mathrm{Y}$, and no cross-resistance with the other four classes of fungicides tested. However, the three amino acid substitutions characterized in the current study did not include the C239S mutation previously associated with zoxamide resistance in Phytophthora sojae (Cai et al. 2016). Further investigation revealed that zoxamide-resistant mutants or transformants of Phytophthora sojae containing the $\mathrm{C} 239 \mathrm{~S}$ mutation were also highly resistant to ethaboxam (data not shown). This indicates that in addition to the three amino acids detailed in the current study, C239S could represent another important mutation site for ethaboxamresistance. Taken together, the results of the current study reveal useful data that can be used to delay the occurrence and development of ethaboxam resistance in the field and suggest that ethaboxam should be used alternatively or in mixtures with the four other fungicides tested (cymoxanil, metalaxyl, flumorph, and oxathiapiprolin) and that the alternate use of ethaboxam with zoxamide or the two in mixtures would not be recommended.

\section{LITERATURE CITED}

Beakes, G. W., Glockling, S. L., and Sekimoto, S. 2012. The evolutionary phylogeny of the oomycete "fungi". Protoplasma 249:3-19.

Bi, Y., Chen, L., Cai, M., Zhu, S. S., Pang, Z. L., and Liu, X. L. 2014. Two non-target recessive genes confer resistance to the anti-oomycete microtubule inhibitor zoxamide in Phytophthora capsici. PLoS One 9:e89336.

Bi, Y., Cui, X., Lu, X., Cai, M., Liu, X. L., and Hao, J. J. 2011. Baseline sensitivity of natural population and resistance of mutants in Phytophthora capsici to zoxamide. Phytopathology 101:1104-1111.

Cai, M., Lin, D., Chen, L., Bi, Y., Xiao, L., and Liu, X. L. 2015. M233I mutation in the $\beta$-tubulin of Botrytis cinerea confers resistance to zoxamide. Sci. Rep. 5:16881.

Cai, M., Miao, J. Q., Song, X., Lin, D., Bi, Y., Chen, L., Liu, X. L., and Tyler, B. M. 2016. C239S mutation in the $\beta$-tubulin of Phytophthora sojae confers resistance to zoxamide. Front. Microbiol. 7:762.

Chen, L., Zhu, S. S., Lu, X. H., Pang, Z. L., Cai, M., and Liu, X. L. 2012. Assessing the risk that Phytophthora melonis can develop a point mutation
(V1109L) in CesA3 conferring resistance to carboxylic acid amide fungicides. PLoS One 7:e42069.

Doench, J. G., Hartenian, E., Graham, D. B., Tothova, Z., Hegde, M., Smith, I., Sullender, M., Ebert, B. L., Xavier, R. J., and Root, D. E. 2014. Rational design of highly active sgRNAs for CRISPR-Cas9-mediated gene inactivation. Nat. Biotechnol. 32:1262-1267.

Dorrance, A. E., Berry, S. A., Anderson, T. R., and Meharg, C. 2008. Isolation, storage, pathotype characterization, and evaluation of resistance for Phytophthora sojae in soybean. Plant Health Prog. 10:1094-1101.

Egan, A. R., Michelotti, E. L., Young, D. H., Wilson, W. J., and Mattioda, H. 1998. RH-7281: A novel fungicide for control of downy mildew and late blight. Pages 335-342 in: Proceedings of Brighton Crop Protection Conference Pests and Diseases. The British Crop Protection Council, Farnham.

Eye, L. L., Sneh, B., and Lockwood, J. L. 1978. Factors affecting zoospore production by Phytophthora megasperma var. sojae. Phytopathology 68: 1766-1768.

Fang, Y. F., and Tyler, B. M. 2016. Efficient disruption and replacement of an effector gene in the oomycete Phytophthora sojae using CRISPR/Cas9. Mol. Plant Pathol. 17:127-139.

Fry, W. 2008. Phytophthora infestans: The plant (and R gene) destroyer. Mol. Plant Pathol. 9:385-402.

Gisi, U., and Sierotzki, H. 2015. Oomycete fungicides: Phenylamides, quinone outside inhibitors, and carboxylic acid amides. Pages 145-174 in: Fungicide Resistance in Plant Pathogens. H. Ishii and D. W. Hollomon, eds. Springer, Japan.

Gray, M. A., Hao, W., Förster, H., and Adaskaveg, J. E. 2018. Baseline sensitivities of new fungicides and their toxicity to selected life stages of Phytophthora species from citrus in California. Plant Dis. 102:734-742.

Haas, B. J., Kamoun, S., and Nusbaum, C. 2009. Genome sequence and analysis of the Irish potato famine pathogen Phytophthora infestans. Nature 461:393-398.

Ho, H. H., and Hickman, C. J. 1967. Asexual reproduction and behavior of zoospores of Phytophthora megasperma var. sojae. Can. J. Bot. 45: 1963-1981.

Islam, S., Middya, R., Mondal, B., and Khatua, D. C. 2018. Effect of fungicide of late blight of potato. Int. J. Curr. Microbiol. Appl. Sci. 7:20-25.

Kamoun, S. 2003. Molecular genetics of pathogenic oomycetes. Eukaryot. Cell 2:191-199.

Kamoun, S., Furzer, O., Jones, J. D., Judelson, H. S., Ali, G. S., Dalio, R. J., Roy, S. G., Schena, L., Zambounis, A., Panabières, F., Cahill, D., Ruocco, M., Figueiredo, A., Chen, X., Hulvey, J., Stam, R., Lamour, K., Gijzen, M., Tyler, B. M., Grünwald, N. J., Mukhtar, M. S., Tomé, D. F., Tör, M., Van Den Ackerveken, G., McDowell, J., Daayf, F., Fry, W. E., LindqvistKreuze, H., Meijer, H. J., Petre, B., Ristaino, J., Yoshida, K., Birch, P. R., and Govers, F. 2015. The top 10 oomycete pathogens in molecular plant pathology. Mol. Plant Pathol. 16:413-434.

Kaufmann, M. J., and Gerdemann, J. W. 1958. Root and stem rot of soybean caused by Phytophthora sojae n. sp. Phytopathology 48:201-208.

Kim, B. S., Zhang, X. Z., Chung, E. K., Kim, D. S., Chun, S. J., and Choi, W. B. 2003. Sensitivity of Phytophthora infestans isolates to fungicides metalaxyl and ethaboxam in Korea. Plant Pathol. J. 19:143-147.

Kim, D., Chun, S., Jeon, J., Lee, S., and Joe, G. 2004. Synthesis and fungicidal activity of ethaboxam against oomycetes. Pest Manag. Sci. 60:1007-1012.

Kim, D. S. 2001. Ethaboxam-Its fungicidal activities as an Oomycetes fungicide. Pages 96-100 in: Proceedings of the International Workshop on Potato Late Blight. National Alpine Agricultural Experiment Station, RDA, Pyongchang, Korea.

Kim, D. S., Lee, Y. S., Chun, S. J., Choi, W. B., Lee, S. W., Kim, G. T., Kang, K. G., Joe, G. H., and Cho, J. H. 2002. Ethaboxam: A new oomycete fungicide. Brighton Crop Prot. Conf. Pests Dis. 1:377-382.

Kim, D. S., Prak, H. C., Chun, S. J., Yu, S. H., Choi, K. J., Oh, J. H., Shin, K. H., Koh, Y. J., Kim, B. S., Hahm, Y. I., and Chung, B. K. 1999. Field performance of a new fungicide ethaboxam against cucumber downy mildew, potato late blight and pepper Phytophthora blight in Korea. Plant Pathol. J. 15:48-52.

Lamour, K. H., Mudge, J., Gobena, D., Hurtado-Gonzales, O. P., Schmutz, J., Kuo, A., Miller, N. A., Rice, B. J., Raffaele, E., Cano, L. M., Platt, D., Salamov, A., Savidor, A., Sharma, R., Stam, R., Storey, D., Thines, M., Win, J., Haas, B. J., Dinwiddie, D. L., Jenkins, J., Knight, J. R., Affourtit, J. P., Han, C. S., Chertkov, O., Lindquist, E. A., Detter, C., Grigoriev, I. V., Kamoun, S., and Kingsmore, S. F. 2012. Genome sequencing and mapping reveal loss of heterozygosity as a mechanism for rapid adaptation in the vegetable pathogen Phytophthora capsici. Mol. Plant-Microbe Interact. 25:1350-1360.

Lu, X. H., Zhu, S. S., Bi, Y., Liu, X. L., and Hao, J. J. 2010. Baseline sensitivity and resistance-risk assessment of Phytophthora capsici to iprovalicarb. Phytopathology 100:1162-1168.

Martinez, C., Lévesque, C. A., Bélanger, R. R., and Tweddell, R. J. 2005. Evaluation of fungicides for the control of carrot cavity spot. Pest Manag. Sci. 61:767-771. 
Mei, X. Y., Yang, M., Ding, X. P., Bi, Y., Chen, L., Deng, W. P., Dong, Y. M., Su, Y., He, X. H., Zhu, S. S., and Liu, X. L. 2014. Proteomic analysis of zoxamideinduced changes in Phytophthora cactorum. Pestic. Biochem. Physiol. 113:31-39.

Phillips, A. J., Anderson, V. L., Robertson, E. J., Secombes, C. J., and Van West, P. 2008. New insights into animal pathogenic oomycetes. Trends Microbiol. 16:13-19.

Ra, C. S., Rew, Y. S., and Cho, W. B. 1995. Synthesis and fungicidal activity of novel 2-aminothiazole carboxamide derivatives. Korean J. Med. Chem. 5:72-75.

Thines, M., and Kamoun, S. 2010. Oomycete-plant coevolution: Recent advances and future prospects. Curr. Opin. Plant Biol. 13:427-433.

Tyler, B. M. 2007. Phytophthora sojae: Root rot pathogen of soybean and model oomycete. Mol. Plant Pathol. 8:1-8.

Uchida, M., Roberson, R. W., Chun, S. J., and Kim, D. S. 2005. In vivo effects of the fungicide ethaboxam on microtubule integrity in Phytophthora infestans. Pest Manag. Sci. 61:787-792.

Whisson, S. C., Fonné-Pfister, R., and Csukai, M. 2011. Molecular approaches to elucidate pathways and sites of' fungicide resistance in oomycetes//
Modern fungicides and antifungal compounds VI. Pages 91-102 in: 16th International Reinhardsbrunn Symposium, Deutsche Phytomedizinische Gesellschaft eV Selbstverlag, Friedrichroda, Germany.

Whitham, S. A., Qi, M. S., Innes, R. W., Ma, W. B., Lopes-Caitar, V., and Hewezi, T. 2016. Molecular soybean-pathogen interactions. Annu. Rev. Phytopathol. 54:443-468.

Yoshida, K., Schuenemann, V. J., Cano, L. M., Pais, M., Mishra, B., Sharma, R., Lanz, C., Martin, F. N., Kamoun, S., Krause, J., Thines, M., Weigel, D., and Burbano, H. A. 2013. The rise and fall of the Phytophthora infestans lineage that triggered the Irish potato famine. eLife 2:e00731.

Young, D. H. 2007. Zoxamide, an anti-tubulin fungicide for control of oomycete pathogens. Mod. Cop Prot. Compd. 16:3.

Young, D. H. 2015. Anti-tubulin agents. Pages 93-103 in: Fungicide Resistance in Plant Pathogens. Springer, Tokyo.

Zhang, X. Z., Ryu, K. Y., Kim, J. S., Cheon, J. U., and Byung, S. 2005. Changes in the sensitivity to metalaxyl, dimethomorph and ethaboxam of Phytophthora infestans in Korea. Plant Pathol. J. 21:33-38.

This article was modified on 19Aug 2020. 
ERRATUM / Volume 109, Number 12, 2019 / PHYTO-01-19-0032-R

In the article "Point Mutations in the $\beta$-Tubulin of Phytophthora sojae Confer Resistance to Ethaboxam" by Qin Peng, Zhiwen Wang, Yuan Fang, Weizhen Wang, Xingkai Cheng, and Xili Liu, one of the Petri dish images in Figure 5 was duplicated inadvertently. This error did not impact the results or conclusions of the study. The corrected Figure 5 is shown below.

Revised Figure 5

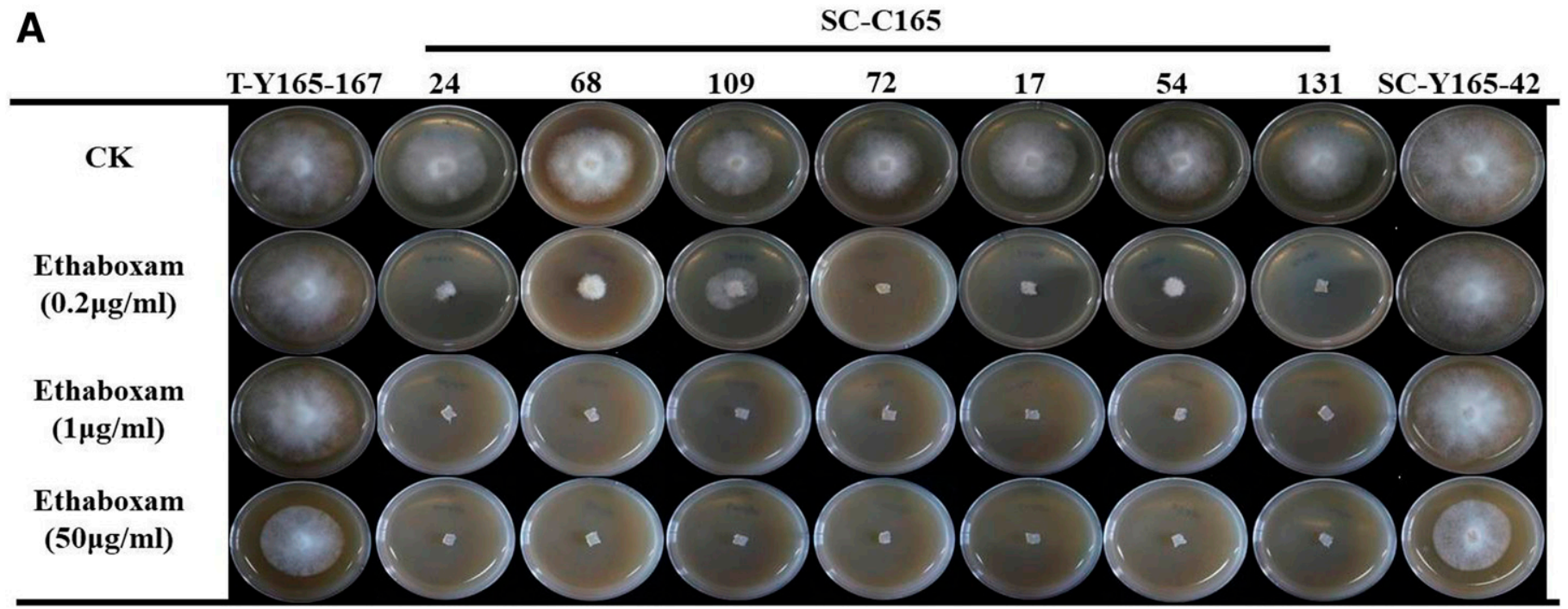

B

SC-I258

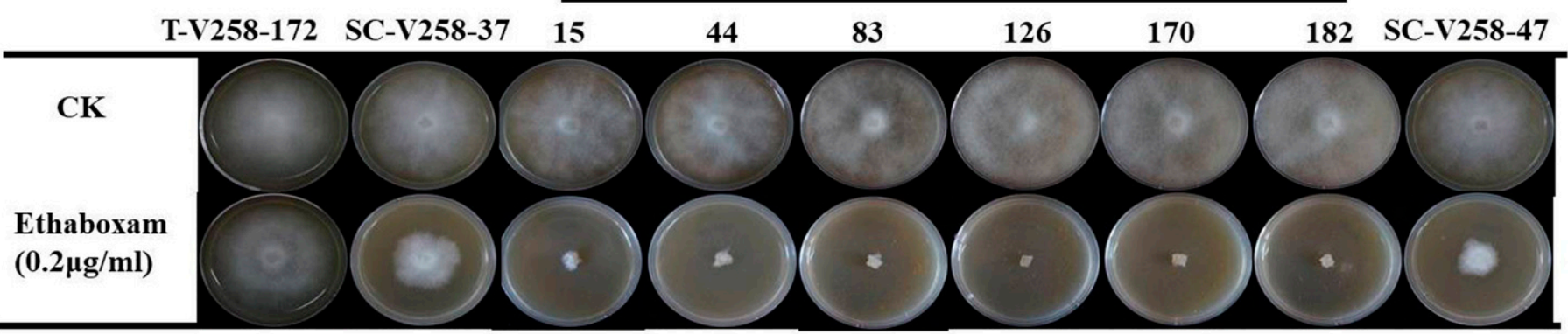

C

\section{SC-Q8}

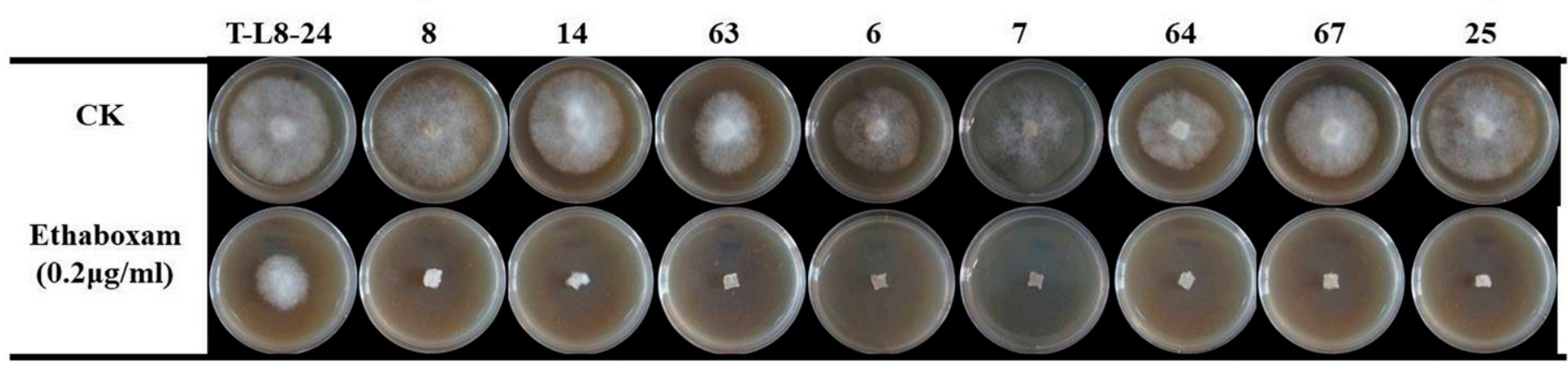

Fig. 5. Mycelial growth of site-complemented transformants of Phytophthora sojae on ethaboxam-amended V8 medium. A, The site-complemented transformants from T-Y165-167. B, The site-complemented transformants from T-V258-172. C, The site-complemented transformants from T-L8-24. The figure is a composite of 72 individual Petri dish images. 
Previously Published Version

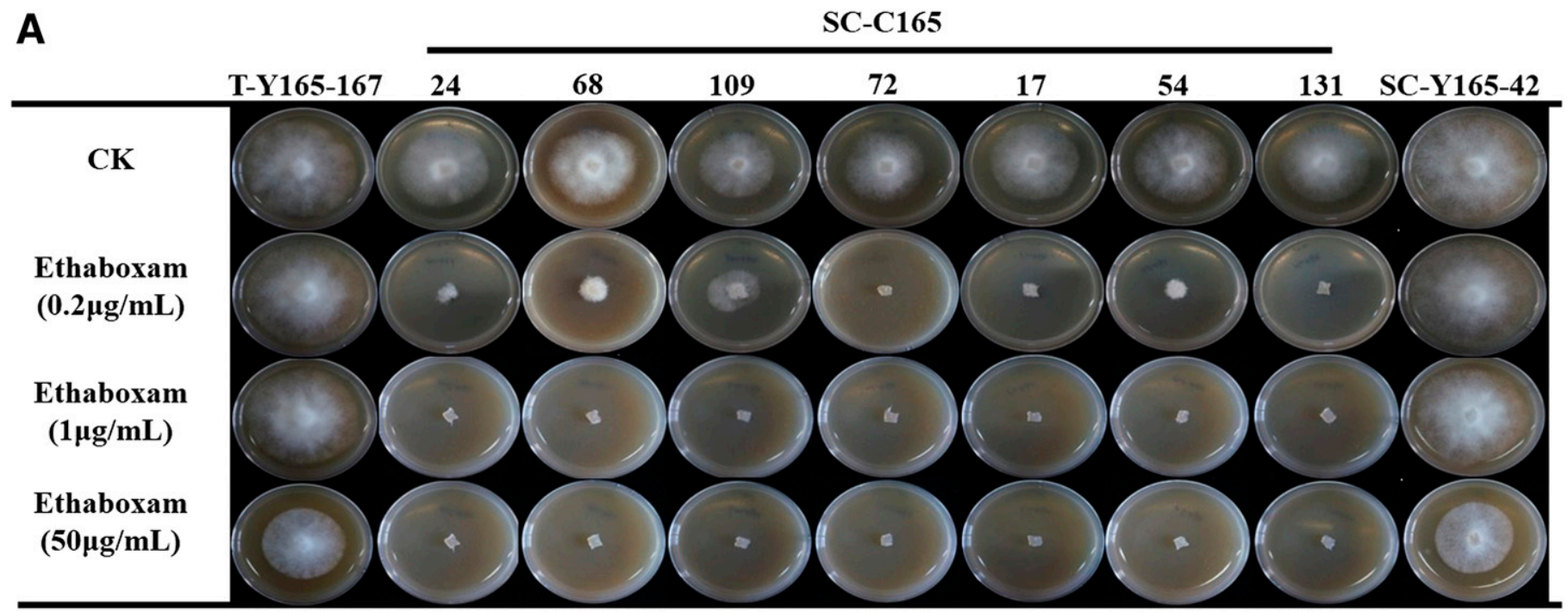

B

SC-I258
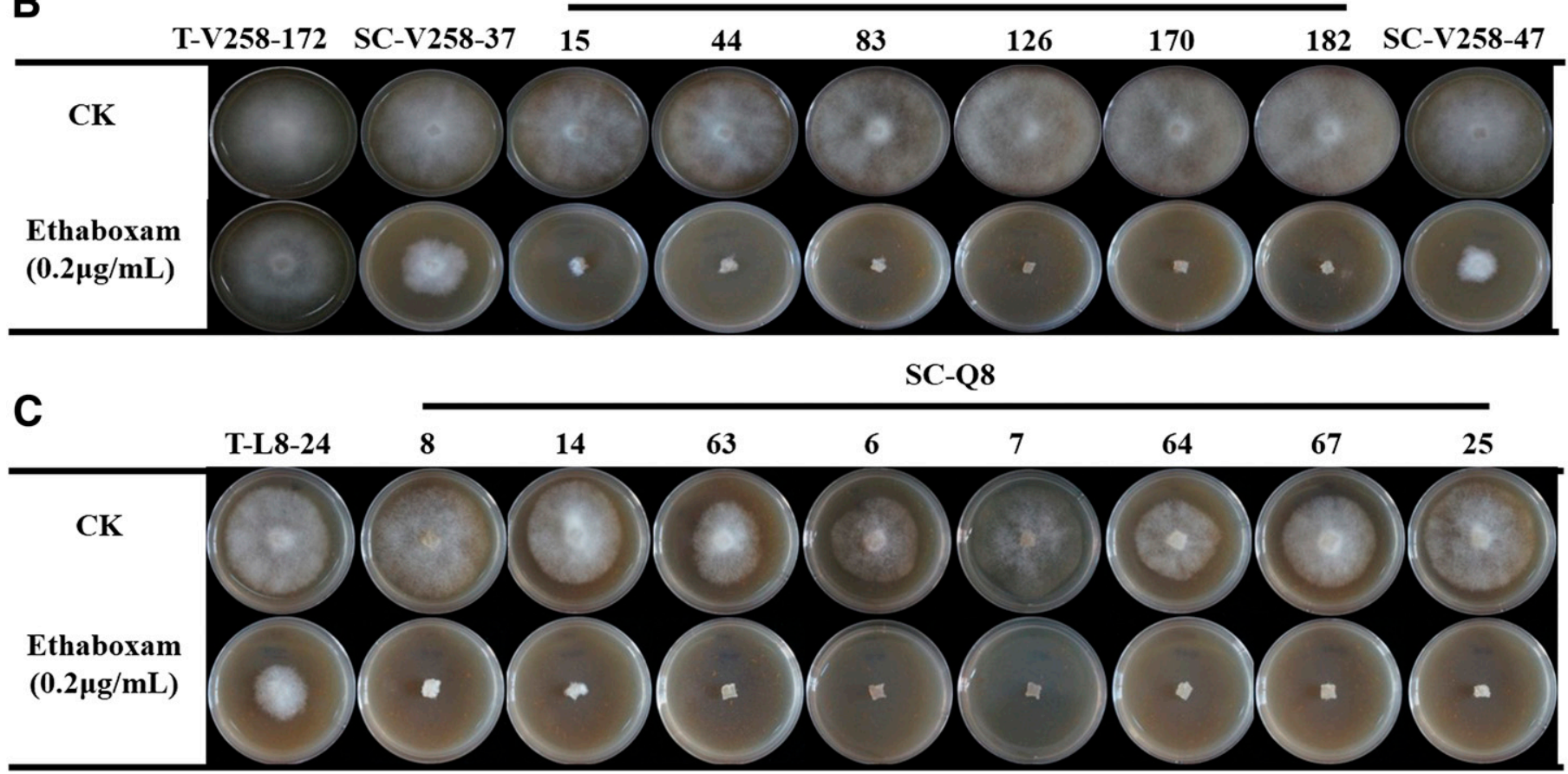

Fig. 5. Mycelial growth of site-complemented transformants of Phytophthora sojae on ethaboxam-amended V8 medium. A, The site-complemented transformants from T-Y165-167. B, The site-complemented transformants from T-V258-172. C, The site-complemented transformants from T-L8-24. 